\title{
Acoustic detection of North Pacific right whales in a high-traffic Aleutian Pass, 2009-2015
}

\author{
Dana L. Wright ${ }^{1,2, *}$, Manuel Castellote ${ }^{1,2}$, Catherine L. Berchok ${ }^{2}$, Dimitri Ponirakis ${ }^{3}$, \\ Jessica L. Crance ${ }^{2}$, Phillip J. Clapham ${ }^{2}$
}

\author{
${ }^{1}$ University of Washington, Joint Institute for the Study of Atmosphere and Ocean, 3737 Brooklyn Ave NE, Seattle, \\ WA 98105, USA \\ ${ }^{2}$ NOAA NMFS AFSC, Marine Mammal Laboratory, 7600 Sand Point Way NE, Seattle, WA 98115, USA \\ ${ }^{3}$ Bioacoustics Research Program, Cornell Laboratory of Ornithology, Cornell University, 159 Sapsucker Woods Road, \\ Ithica, NY 14850, USA
}

\begin{abstract}
Little is known about the winter distribution of the Critically Endangered eastern population of North Pacific right whale Eubalaena japonica (NPRW), but it has been proposed that the eastern Aleutian Islands, specifically Unimak Pass, constitute a plausible migratory route for individuals. This is a major point of concern given the high shipping traffic in this pass. Therefore, a long-term acoustic recorder was deployed in Unimak Pass (2009-2015), and NPRWs were identified using the 'up' and 'gunshot' call types during manual review of data (8188 recorded hours). Calls were grouped into periods of hypothesized migration (Dec-Feb and Mar-May) and other (Jun-Aug and Sep-Nov). Overall, NPRW calling was intermittent and clustered in time, suggestive of a few individuals transiting the area across seasons. Upcalls $(n=31)$ were detected on $7 \mathrm{~d}$ and occurred most often during Dec-Feb, whereas gunshots ( $\mathrm{n}=465$ ) were detected on $32 \mathrm{~d}$, occurring in all months except February and October. The majority of individual gunshot calls ( $\mathrm{n}=306$ ) occurred over $3 \mathrm{~d}$ in Dec-Feb 2014-15. Because of this pattern, gunshot calling occurred on more days during Jun-Aug, while more individual calls occurred during Dec-Feb. Diel and seasonal trends in hourly call detection rates were absent. Together, these data confirm that NPRW use Unimak Pass both during and outside of the assumed migratory period. Pervasive vessel noise throughout the study highlights near constant potential for interaction with anthropogenic disturbance. Consistently higher vessel noise during Dec-Feb suggests that this species is most vulnerable during the assumed migratory period.
\end{abstract}

KEY WORDS: Eubalaena japonica $\cdot$ Passive acoustic $\cdot$ Bioacoustics $\cdot$ Gulf of Alaska $\cdot$ Bering Sea • Vessel traffic

\section{INTRODUCTION}

The eastern population of the North Pacific right whale Eubalaena japonica (hereafter NPRW) likely remains one of the most critically endangered baleen whale populations in the world. Extensive historical whaling in the 19th century followed by illegal catches by the Soviet Union in the 1960s (Scarff 2001, Shelden et al. 2005, Ivashchenko \& Clapham 2012) has left the population numbering in the tens of individuals (Wade et al. 2011a). Historical data suggest

*Corresponding author: dana.wright@noaa.gov

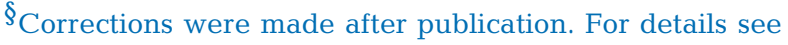
www.int-res.com/abstracts/esr/v37/c_p77-90/

This corrected version: October 18, 2018 that the seasonal (May-Oct) distribution of NPRWs ranged from the Gulf of Alaska (GOA) north to the Bering Strait (Scarff 1991, Shelden et al. 2005, Josephson et al. 2008). Despite extensive effort, the majority of NPRW sightings and acoustic detections in the past few decades have been isolated to the southeastern Bering Sea (SEBS; Shelden et al. 2005, Wade et al. 2006, 2011b, Munger et al. 2008, Rone et al. 2012). Additional rare detections have also been observed opportunistically in the GOA and south of the Aleutian Islands (Shelden et al. 2005, Wade et al.

(C) The authors and outside the USA, the US Government 2018. Open Access under Creative Commons by Attribution Licence. Use, distribution and reproduction are unrestricted. Authors and original publication must be credited.

Publisher: Inter-Research · www.int-res.com 
2011b, Širović et al. 2015, Ford et al. 2016). NPRW sightings in the vicinity of Unimak Pass since 2000 have been extremely rare despite effort in this region (e.g. Figs. 9 \& 10 in Shelden et al. 2005), consisting of one sighting southeast of Unimak Pass in August 2000 (Mellinger et al. 2004), one sighting north of Unimak Pass on 12 April 1993 (Shelden et al. 2005), one sighting south of Unimak Pass in September 2004 (Wade et al. 2011a), and a sighting of 12 NPRWs just north of Unimak Pass in October 2005 (NMFS 2006).

Winter survey effort of NPRW has been limited due to weather and funding constraints (Shelden et al. 2005, Munger et al. 2008). Nevertheless, previous acoustic data from the SEBS (2000-2006) recorded an absence of NPRW during winter (Jan-Apr; Munger et al. 2008), which is consistent with the hypothesis that NPRW seasonally migrate south of the Aleutian Chain (Gendron et al. 1999, Clapham et al. 2004, Kennedy et al. 2012). Migration to lower latitude regions for breeding and calving has been documented for congeneric right whale populations (Matthews 1983, Kraus et al. 1986). However, recent efforts in the Gulf of Maine have discovered winter aggregations of North Atlantic right whales Eubalaena glacialis (NARW; Cole et al. 2013, Bort et al. 2015), suggesting a more complicated life history strategy for right whale species than previously thought. To date, no migration routes or breeding/calving grounds of NPRWs are known. One individual NPRW has been sighted in the SEBS and Hawaii (Kennedy et al. 2012), tentatively supporting the migratory hypothesis and suggesting a potential overwintering ground. Data on winter occurrence and distribution are therefore essential to understand the basic life history of this Critically Endangered species (Reilly et al. 2008) and to formulate effective management strategies.
The passes between the islands of the eastern Aleutians are considered the most plausible migratory route for individuals moving between the SEBS and lower latitudes. Sightings in the pass in winter (January 1964; Ivashchenko \& Clapham 2012) combined with spring observations as early as April (Shelden et al. 2005) led researchers to suggest that Unimak Pass may be part of a migratory route of this species. This raises a major concern given the high year-round vessel traffic through this narrow channel ( 16 km wide); for example, 1961 deep-draft vessels involved in international trade were estimated to have made 4615 transits through Unimak Pass in 2012 (Nuka Research and Planning Group 2014). Of these transits, the majority of vessels were cargo vessels $(60 \%)$ followed by container vessels $(24 \%)$. This study excluded fishing, military, ferry, tugs, and barges, as well as smaller vessels not equipped with an Automated Identification System.

Given the small population size of NPRW $(\mathrm{n} \approx 30)$ and high vessel traffic in Unimak Pass, a long-term acoustic recorder has been annually deployed in this Aleutian Pass since 2009 to monitor for NPRWs. Based upon previous observations and the whaling catch data mentioned above, we hypothesized that if NPRW were present, then their acoustic detections would occur between December and May, consistent with seasonal entry into or exit from the Bering Sea.

\section{MATERIALS AND METHODS}

\section{Equipment and processing}

A sub-surface mooring with passive acoustic recorder was deployed annually from 2009 in a depression in the center of Unimak Pass $\left(54.43^{\circ} \mathrm{N}\right.$, $165.27^{\circ} \mathrm{W}_{i} \sim 165 \mathrm{~m}$; Table 1, Fig. 1). The mooring com-

Table 1. List of all passive acoustic recorders used in analysis, 2009-2015. Rec on: recorder on, time of each recording session (continuous minutes); Period: time between each recording session length of each recording cycle

\begin{tabular}{|c|c|c|c|c|c|c|c|c|c|c|}
\hline Deployment & $\begin{array}{c}\text { Latitude } \\
\left({ }^{\circ} \mathrm{N}\right)\end{array}$ & $\begin{array}{l}\text { Longitude } \\
\left({ }^{\circ} \mathrm{W}\right)\end{array}$ & $\begin{array}{l}\text { Recorder } \\
\text { start date }\end{array}$ & $\begin{array}{l}\text { Recorder } \\
\text { end date }\end{array}$ & $\begin{array}{c}\text { Days } \\
\text { with data }\end{array}$ & $\begin{array}{l}\text { Sampling } \\
\text { rate }(\mathrm{Hz})\end{array}$ & $\begin{array}{c}\text { Rec on } \\
\text { (min) }\end{array}$ & $\begin{array}{c}\text { Period } \\
\text { (min) }\end{array}$ & $\frac{\mathrm{h}}{\mathrm{d}^{-1}}$ & $\begin{array}{c}\text { Total } \\
\mathrm{h}\end{array}$ \\
\hline $2009-10^{a}$ & 54.427 & 165.266 & 4 Aug 2009 & 1 Aug 2010 & 363 & 4096 & 4 & 60 & 1.6 & 581 \\
\hline $2011-12^{\mathrm{a}}$ & 54.429 & 165.268 & 9 Sep 2011 & 9 Aug 2012 & 335 & 4096 & 4 & 60 & 1.6 & 536 \\
\hline 2012-13 & 54.429 & 165.268 & 10 Aug 2012 & 12 Sep 2013 & 398 & 16384 & 85 & 300 & 6.8 & 2706 \\
\hline 2013-14 & 54.428 & 165.268 & 18 Sep 2013 & 20 Oct 2014 & 397 & 16384 & 80 & 300 & 6.4 & 2541 \\
\hline $2014-15$ & 54.428 & 165.268 & 22 Oct 2014 & 28 Sep $2015^{b}$ & 341 & 16384 & 80 & 300 & 6.4 & 2182 \\
\hline
\end{tabular}




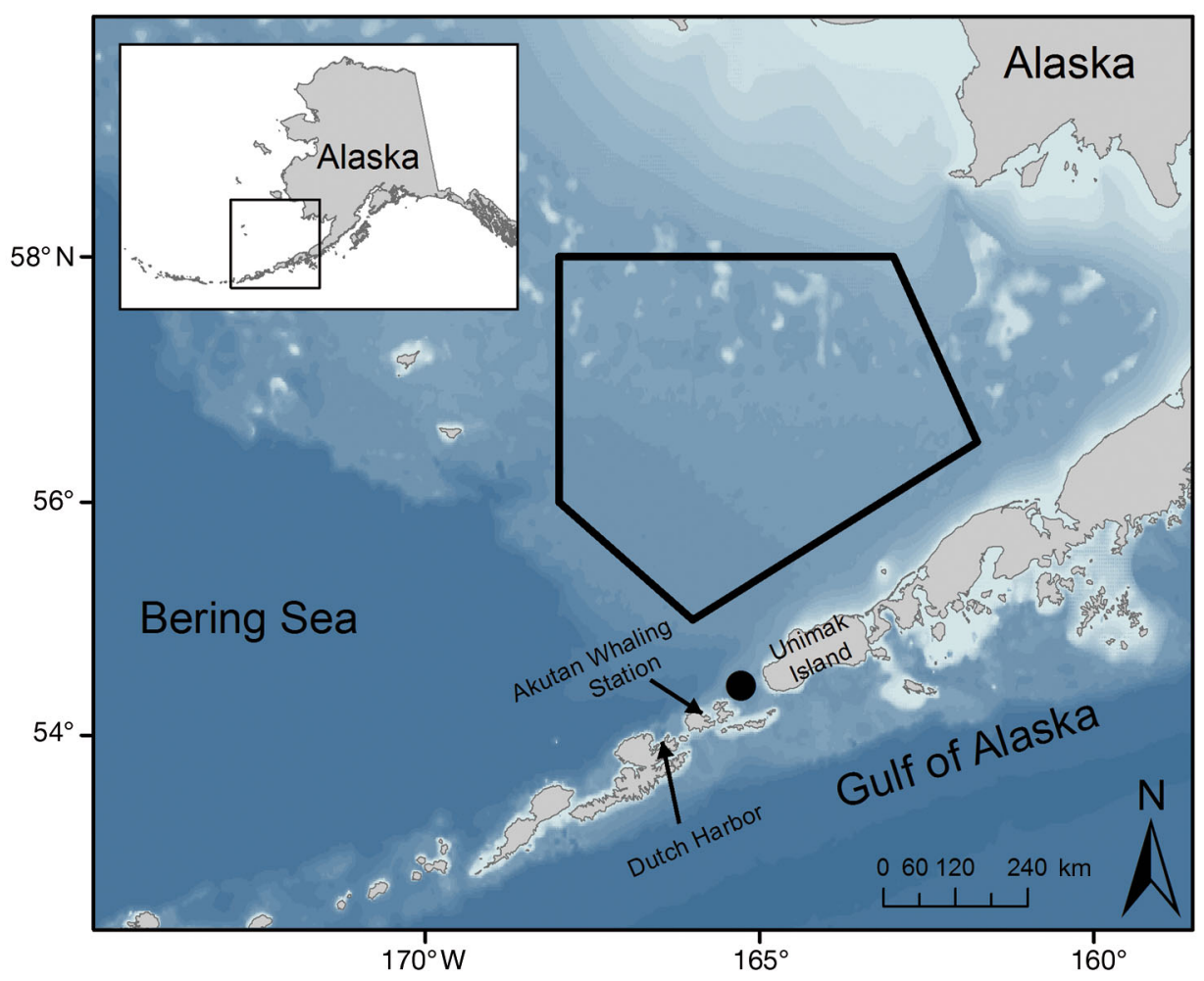

Fig. 1. Location of long-term passive acoustic recorder used in the analysis (black pentagon). Black pentagon demarcates the eastern North Pacific right whale Critical Habitat. Inset: map of Alaska; black square demarcates southeastern Bering Sea and eastern Aleutian Islands.

prised an anchor, acoustic release, passive acoustic recorder, and 30" $(76 \mathrm{~cm})$ steel subsurface float arranged in a linear configuration (Wright et al. 2018). An Ecological Acoustic Recorder (EAR; Lammers et al. 2008) was used for the first 3 deployments and was replaced in 2012 with an AURAL recorder (Autonomous Underwater Recorder for Acoustic Listening; Multi-Électronique, Rimouski, QC; Table 1). The omnidirectional hydrophone was housed at the top of the recording device facing the sea surface, placing the hydrophone approximately $4 \mathrm{~m}$ and $6 \mathrm{~m}$ above the seafloor, respectively. The sampling period and duty cycle of acoustic recordings varied among deployments (Table 1). Gain, sampling rates, bit depths, frequency ranges, and noise floors for EARs and AURALs are specified in Wright et al. (2018).

Raw data from the recorder were converted into $10 \mathrm{~min}$ sound files (.wav) and downsampled to $1.6 \mathrm{kHz}$ for consistency using the MATLAB 'resample' function. Image files (.png) of spectrograms were pre-generated from the downsampled recordings (FFT 256 with 200 point zero-padding, 0.85 overlap, Hamming window) for the duration of the recording cycle (see Table 1). Each image file displayed 5 lines of data $45 \mathrm{~s}$ long from 0 to $800 \mathrm{~Hz}$ (time grid spacing of $24 \mathrm{~ms}$ and a frequency grid spacing of $3.5 \mathrm{~Hz}$; time analysis resolution of $160 \mathrm{~ms}$, frequency analysis resolution of $6.25 \mathrm{kHz}$ ). This $225 \mathrm{~s}$ segment of data is the analysis interval of the study.

Given that these data were not collected continuously, recording effort varied throughout the study period. Therefore, data were normalized by recording effort (number of analysis intervals with a species or sound source detected/number of intervals recorded), which will be referred to as the percentage of intervals with calls (PIC). It is important to note that, because these are binned data, PIC does not indicate the number of call detections or number of animals vocalizing.

\section{Acoustic analysis and species differentiation}

No autodetection programs were used due to the substantial overlap of call repertoires among baleen whales in the subarctic and North Pacific, the expected high occurrence of humpback whale vocalizations, and low population size of NPRW. Instead, all acoustic data $(100 \%$ of the image files; $1778 \mathrm{~d}$, $8188 \mathrm{~h}$; Table 1) were analyzed manually (by D.L.W.) 
using an in-house MATLAB-based program, SoundChecker, which allows for visual/audio inspection of the spectrogram image files. Consequently, each bin was analyzed concurrently for the following species: bowhead whale Balaena mysticetus, gray whale Eschrichtius robustus, humpback whale Megaptera novaeangliae, minke whale Balaenoptera acutorostrata, NPRW, and walrus Odobenus rosmarus; vessel noise was also marked. SoundChecker operates on the pregenerated image files, indexed for zoom and sound playback functionality. For each image file, 'yes', 'no', or 'maybe' was chosen to indicate whether a species was detected in the interval. 'Yes' was used only to denote intervals the analyst was confident in attributing to a source. The analyst was trained to identify arctic and subarctic sounds using acoustic data from the federally designated right whale Critical Habitat (Fig. 1) and southern Chukchi shelf. Because these data were analyzed for multiple species simultaneously, an interval could be binned for $>1$ species. Only 'yes' intervals are presented here.

Two call types were used to identify NPRWs: the frequency modulated (FM) 'upcall' and the impulsive 'gunshot call'. Upcalls (Fig. 2a) were defined as FM calls with variable frequency and sweep rate characteristics, on average from 80 to $160 \mathrm{~Hz}$ and approximately $1 \mathrm{~s}$ in length (McDonald \& Moore 2002). The upcall classification also included 'down-up' calls as defined by McDonald \& Moore (2002), although no 'down-up' calls were detected in this dataset.

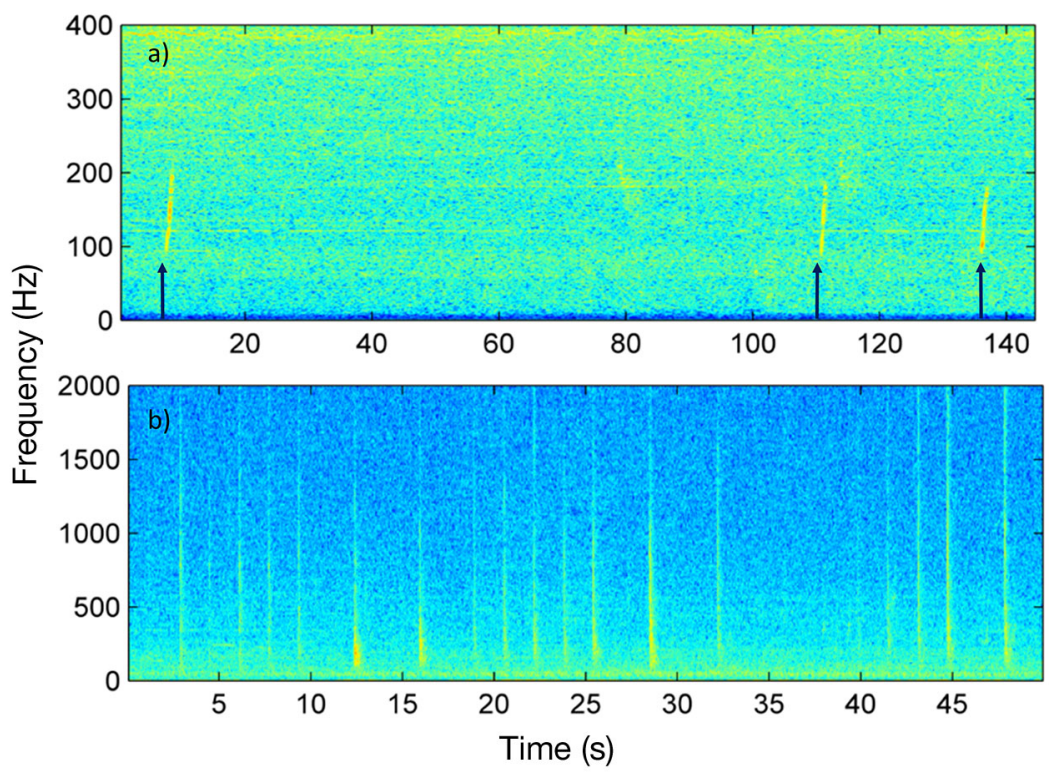

Fig. 2. Spectrograms of North Pacific right whale (a) upcalls (indicated with arrow; 3 Feb 2010) and (b) gunshot calls (24 Dec 2014). The spectrograms have an FFT length of (a) 2048 and (b) 1024. Both spectrograms use a Hamming window and have a $95 \%$ overlap and a sampling rate of $1.6 \mathrm{kHz}$
The upcall is the most common FM call type of right whale species and is assumed the contact call among conspecifics (Cummings et al. 1972, Clark 1982, Matthews et al. 2001, 2014, McDonald \& Moore 2002). Right whale gunshot calls are defined as brief $(<1 \mathrm{~s})$, broadband, impulsive sounds $(20 \mathrm{~Hz}$ to 20 kHz; Clark 1983, Parks \& Tyack 2005, Crance et al. 2017). NPRW gunshot calls $(\sim 300 \mathrm{~ms} ; 50 \mathrm{~Hz}$ to $6 \mathrm{kHz}$ ) are produced by both sexes (Crance et al. 2017) and could occur irregularly as single calls or in patterned gunshot bouts of $>10$ calls with consistent inter-call intervals ( 0.5 to $5 \mathrm{~s}$ apart; Fig. $2 \mathrm{~b}$; Crance et al. 2017).

To differentiate among anticipated baleen whale species, call characteristics (e.g. fundamental frequency, inter-call interval (ICI), bout pattern, call duration) and contextual clues (e.g. association with conspecific sounds, proximity to nonspecific sounds) were used in tandem. In general, right and humpback whale upsweeps were distinguished using the criteria from Wright et al. (2018), namely (1) the presence of conspecific sounds; (2) that humpback whale vocalizations often occur in repetitive patterns and can produce song, even outside of the breeding season (Payne \& McVay 1971, Clark \& Clapham 2004); (3) that humpback sounds often recur within a period of 3 to $5 \mathrm{~s}$ (Thompson et al. 1986, McSweeney et al. 1989), whereas right whale vocalizations are often irregular ( $>5 \mathrm{~s}$ ) with more time between bouts ( 3 to $>60 \mathrm{~min}_{\text {; }}$ McDonald \& Moore 2002, Crance et al. 2017); and (4) that humpback whale vocalizations often vary within a bout (Thompson et al. 1986), whereas NPRW produce sequences of solely upcalls in sets of 3 to 50 (>5 s apart; McDonald \& Moore 2002).

Gunshots were distinguished from other impulsive sounds spectrographically and aurally in addition to contextual clues. For example, killer whale Orcinus orca pulses sound like lowfrequency echolocation, while gunshot calls sound reverberant. However, it is difficult to differentiate non-patterned gunshot calls from impulsive sounds such as slaps and breaches (Parks et al. 2005). This is further complicated by the fact that NPRW have been repeatedly observed in the same aggregation as humpback whales (Brownell et al. 2001, Mellinger et al. 2004, Wade et al. 2011b). Therefore, co-occurrence of sounds of both spe- 
cies in a given period would not be unrealistic. In these cases, and other times and locations when sounds could not be attributed to species with confidence, the intervals were binned as 'maybe' for all probable species and were consequently excluded from analysis. A liberal approach was used in binning intervals with potential species to 'maybe' so that potential calls were not lost in the large dataset (8188 recorded hours). A conservative approach was used in positively binning intervals to potential species (i.e. marking 'yes') given the present paucity of right whales and anticipated high presence of humpback whale detections; only 'yes' intervals are presented here.

\section{Statistical analysis}

All statistical analyses were conducted in the program R (R Core Team 2015). All averages are presented as $\pm 1 \mathrm{SD}$, and all hypothesis tests were made with a significance level of $\alpha \leq 0.05$. Data were grouped by 'mooring-year' for this study. Each mooring-year consisted of the time from 4 August to 3 August of the following year due to the earliest deployment start date of the dataset (4 August 2009; Table 1). An exception occurred in mooring-year 2011-12, which included data from 4 August 2011 to 9 August 2012, because of the transition from EAR to AURAL recorder (and subsequent change in duty cycle; Table 1). Subsequently, mooring-year 2012-13 started on 10 August 2012. Finally, only data up to 3 August 2015 were used in analyses for consistency (Table 1).

In addition to mooring-year, data were grouped by periods of time when NPRW were hypothesized to be transiting between the Bering Sea and GOA, possibly toward breeding grounds. NPRW were assumed more likely to be in the passes during DecemberFebruary and March-May (Clapham et al. 2004, Munger et al. 2008, Smith et al. 2012) and less likely to be transiting through the passes in June-August and September-November. These groupings will be referred to in the manuscript as seasonal timeframes (Dec-Feb, Mar-May, Jun-Aug, Sep-Nov).

Following manual analysis of the bulk data, individual NPRW calls were subsequently counted to explore variability in individual calls. Variability in the total number of days and total number of calls was explored by mooring-year (2009-10, 2011-12, 2012-13, 2013-14, and 2014-15) and seasonal timeframe (Dec-Feb, Mar-May, Jun-Aug, Sep-Nov) using non-parametric Kruskal Wallis tests (package 'stats'). Given there were $3 \mathrm{~d}$ with outlier gunshot calling (24-25 December 2014 and 3 January 2015; Figs. 3 \& 4), subsequent analysis was run excluding these data for comparison.

Variability in call detection rate (call detections $\mathrm{h}^{-1}$ ) was also explored. For this study, hourly call detection rate was defined as the number of NPRW calls detected within a given hour on a given day. Because of the duty cycle, only calls that occurred within 60 continuous minutes of sampling were included in call detection rate analysis. Consequently, all EAR data were excluded as well as the last 20 or 25 min of every 80 or 85 min sampling period of the AURAL data (Table 1). Variability in call detection rates was explored by seasonal timeframe (Dec-Feb, MarMay, Jun-Aug, Sep-Nov) and light regime (twilight, daylight, night) using Kruskal Wallis tests. To determine light regimes, calls were classified into one of 3 time-periods: twilight (including dawn and dusk, where sun altitude was between -12 and $0^{\circ}$ ), daylight (where sun altitude was $>0^{\circ}$ ), and night (where sun altitude was $<-12^{\circ}$ ); astronomical data of the sun relative to the Earth's horizon were obtained from the US Navy Observatory website (http://aa.usno.navy. mil). Given there were $3 \mathrm{~d}$ with outlier gunshot calling (24-25 December 2014 and 3 January 2015; Fig. 4), subsequent analysis was run excluding these data for comparison. It is important to emphasize that the call detection rates reported here are relative measures of NPRW calling because neither the period of recording when right whales were present nor the number of whales is known (i.e. whales could have been present and silent or absent for a portion of the sampled hour).

\section{Vessel noise analysis}

Because of the pervasive vessel noise throughout the study period, annual and seasonal variability in vessel noise in the Unimak Pass acoustic environment was explored for the frequency ranges of NPRW upcalls (80 to $160 \mathrm{~Hz}$ ) and gunshot calls (50 Hz to $5 \mathrm{kHz}$ ). Only data from AURAL recorder deployments were used in the analysis (2012 to 2015) for consistency (Table 1). All data were processed using Cornell's noise analysis software tool, referred to as the Acoustic Ecology Toolbox (AET: originally referred to as SEDNA; Dugan et al. 2011). Individual contribution of sound sources (vessel) was measured by calculating the spectral empirical probability density (Merchant et al. 2013) in $1 \mathrm{~h}$ averages and power spectral density percentiles 
(1st, 25th, 50th, 75th and 99th) using only file segments that included exclusively that one sound source (e.g. vessel noise). AET analysis resulted in an output of sound level measurements at $1 \mathrm{~h}, 1 \mathrm{~Hz}$, and $1 \mathrm{~dB}$ (re $1 \mu \mathrm{PA}$ ) resolutions. The 50th power spectral density percentiles (median) were then compared for the sound source (vessel noise) within the NPRW upcall bands and gunshot call bands. The 50th power spectral density percentile for vessel noise in the upcall frequency range (80 to $160 \mathrm{~Hz}$ ) was also compared to the baseline conditions for mooring-year 2012-13. In this study, baseline conditions correspond to periods where no obvious sound sources were identified visually and aurally on the spectrographic analysis. These baseline periods were processed following the same methods described above for vessel presence.

\section{RESULTS}

A total of $1778 \mathrm{~d}$ of data were used in the analysis (Table 1, Fig. 3). Mooring year 2010-11 was excluded from analysis due to a faulty hydrophone. Over the course of the study, 480 NPRW vocalizations were detected over the $37 \mathrm{~d}$ with detections, 31 individual upcalls over $7 \mathrm{~d}$ ( $0.4 \%$ of days sampled) and 449 gunshot calls over $32 \mathrm{~d}(1.7 \%$ of days sampled; Figs. $3-5)$. Overall, detections were clustered in time and intermittent (Fig. 3). Calling occurred for sequential days only twice: 8-12 August 2009 (all gunshots) and
24-26 December 2014 (upcalls and gunshots; Figs. 3 \& 4). These winter detections (24-25 December 2014) also constitute the only days when both call types were detected on a given day (Fig. 4). For the majority of days with detections (33 of 39), the total number of individual calls was low ( $<5$; Fig. 4). However, the bulk of total number of calls occurred over only 3 d in winter 2014 (398 of 480 total calls; $24-25$ December 2014 and 3 January 2015; Fig. 4).

\section{Mooring-year}

NPRW calls were detected in every mooring-year (Fig. 5). Upcalls occurred in 4 mooring-years (absent in 2013-14) for a similar number of days each year (1-2 di Fig. 5). Furthermore, the number of individual upcalls was similar across mooring-year; the most upcalls occurred in 2012-13 ( $\mathrm{n}=11)$ and the fewest in 2011-12 ( $n=5$; Figs. 4 \& 5). In contrast, gunshots were absent in 2011-12, and the number of days with detections was more variable (4-14 d; Figs. 4 \& 5). Also, the number of individual gunshot calls varied dramatically among mooring-years, with the most gunshot calls in 2014-15 ( $\mathrm{n}=408)$, due to 3 d with outlier calling (24-25 December 2014 and 3 January 2015), and the fewest in 2013-14 ( $=5$; Figs. 4 \& 5). The total number of days with calls varied significantly among mooring-year (Kruskal-Wallis $[\mathrm{KW}]$, degrees of freedom [subscript] $\mathrm{KW}_{4}=$ $11.68, \mathrm{p}=0.02)$. Similarly, the total number of indi-

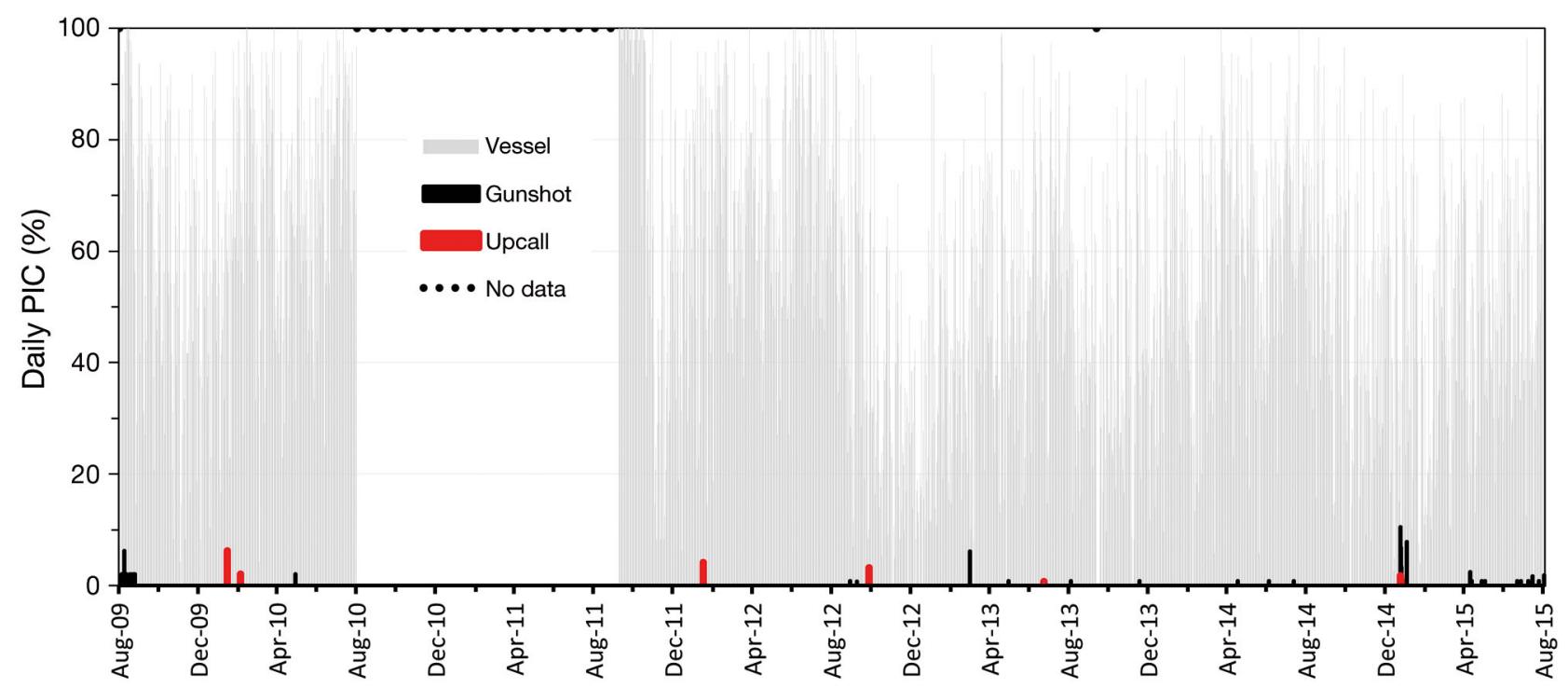

Fig. 3. Daily percentage of intervals with calls (PIC; i.e. the percentage of time intervals [225 s] with positive detections) for vessel noise (light gray), North Pacific right whale upcalls (red), and North Pacific right whale gunshot calls (black), 2009 to 2015. Dotted black line along the top axis indicates days with no data 


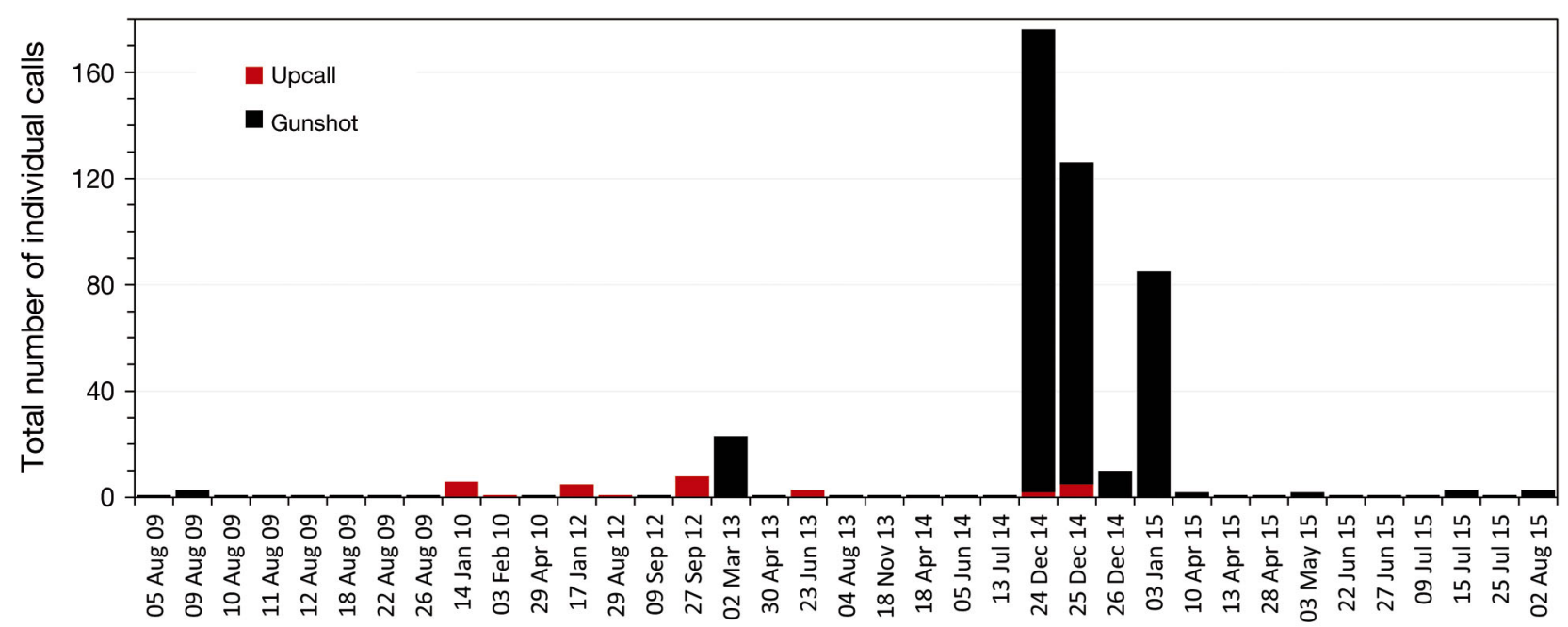

Fig. 4. Total number of individual North Pacific right whale upcalls (red) and gunshot calls (black) for days with call type present
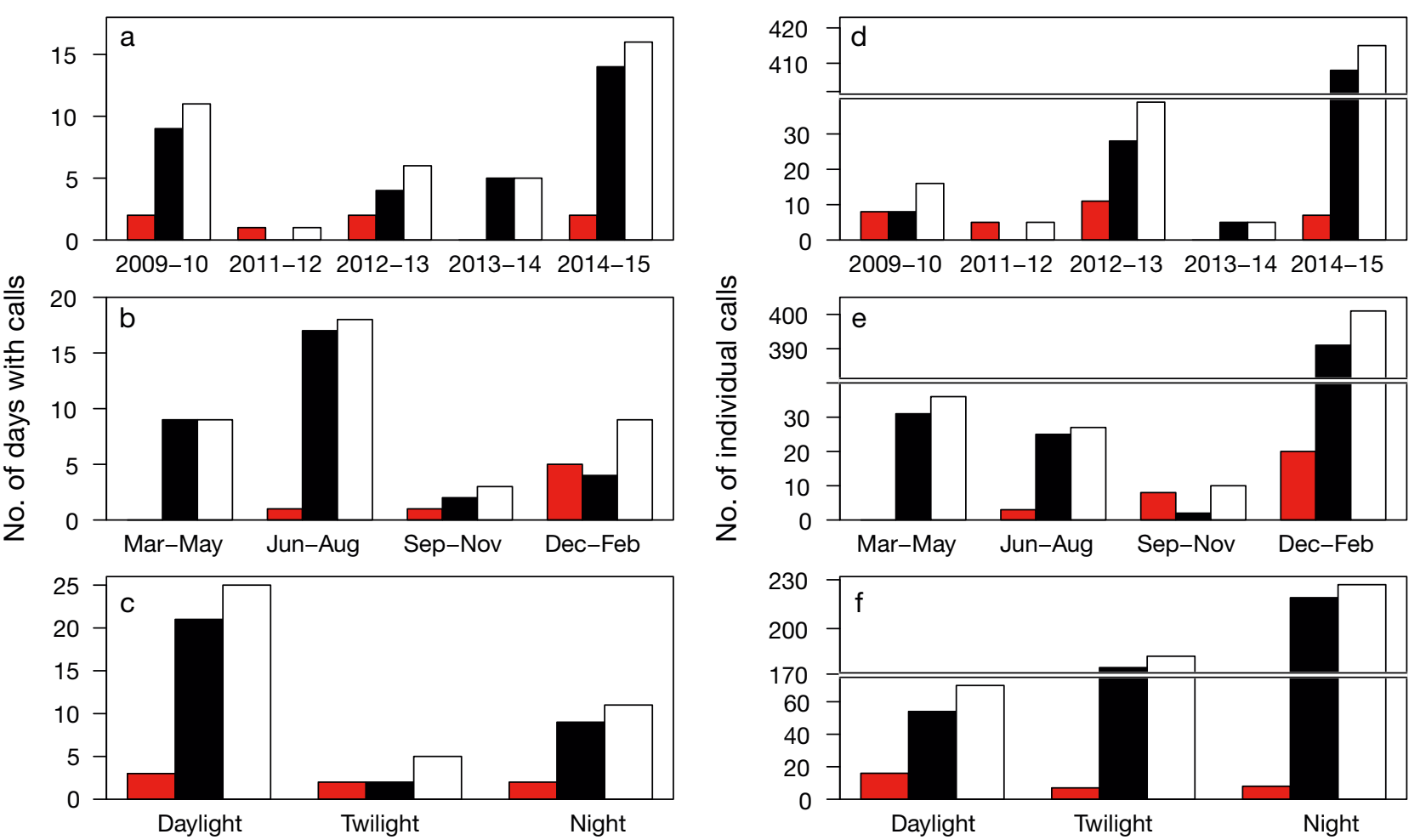

Fig. 5. Total number of $(\mathrm{a}-\mathrm{c})$ days and $(\mathrm{d}-\mathrm{f})$ individual North Pacific right whale calls by call type (upcall: red; gunshot: black, and total calls: white) for $(\mathrm{a}, \mathrm{d})$ mooring-year, $(\mathrm{b}, \mathrm{e})$ seasonal timeframe, and $(\mathrm{c}, \mathrm{f})$ light regime

vidual calls varied by mooring-year when all calls were included $\left(\mathrm{KW}_{4}=11.70, \mathrm{p}=0.02\right)$ and when the outlier gunshot calling (24-25 December 2014 and 3 January 2015; Fig. 4) was excluded $\left(\mathrm{KW}_{4}=10.68\right.$, $\mathrm{p}=0.03$ ). These findings warrant limited interpretation given the variance in duty cycle across the study (Table 1).

\section{Seasonality (timeframes)}

Calls occurred during every seasonal timeframe (Fig. 5). The most days with upcalls occurred in Dec-Feb (5 of $7 \mathrm{~d}$ ), whereas the most days with gunshot calls occurred in Jun-Aug (17 of 32 di Fig. 5). The majority of individual upcalls ( $\mathrm{n}=20$ of 31$)$ occurred in 
Dec-Feb; all other upcalls occurred during 23 June $2012(\mathrm{n}=3)$ and 29 September $2013(\mathrm{n}=8$; Figs. 4 \& 5). The majority of individual gunshot calls also occurred in Dec-Feb ( $\mathrm{n}=391$ of 449), followed by Mar-May $(\mathrm{n}=31)$, Jun-Aug $(\mathrm{n}=25)$, and Sep-Nov ( $=2$; Figs. 4 $\& 5)$. Consequently, significantly more days with calls occurred during Jun-Aug $\left(\mathrm{KW}_{3}=13.71\right.$, $\left.\mathrm{p}=0.003\right)$, while the largest number of individual calls occurred during Dec-Feb when all calls were included $\left(\mathrm{KW}_{3}=\right.$ 13.53, $\mathrm{p}=0.004$ ) and when the $3 \mathrm{~d}$ of outlier gunshot calling (24-25 December 2014 and 3 January 2015) were excluded $\left(\mathrm{KW}_{3}=12.52, \mathrm{p}=0.01\right)$. Hourly call detection rates did not vary significantly by timeframe when all hours were included $\left(\mathrm{KW}_{2}=5.03, \mathrm{p}=0.08\right)$ or when the outlier gunshot calling was excluded $\left(\mathrm{KW}_{3}=\right.$ 7.08, $\mathrm{p}=0.07$; Fig. 6).

\section{Light regime}

Both call types occurred during all light regimes (Fig. 6). Calls occurred most often during daylight

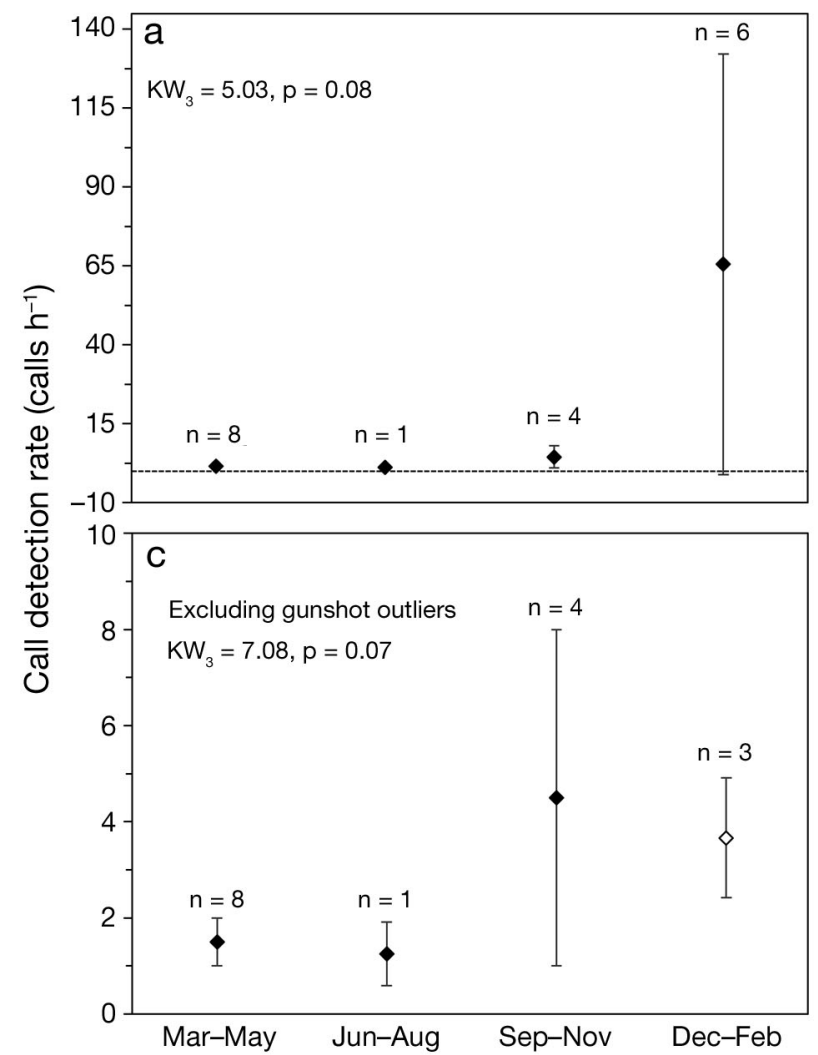

( 3 of $7 \mathrm{~d}$ for upcalls and 21 of $32 \mathrm{~d}$ for gunshots; Fig. 5). This trend was reflected in the total number of upcalls ( $\mathrm{n}=17$ of 31 in daylight; Fig. 5). In contrast, for gunshots, the greatest number of individual calls occurred during the night $(\mathrm{n}=227)$ and the fewest occurred during daylight ( $\mathrm{n}=7$; Fig. 5). Hourly call detection rates did not vary by light regime when all hours were included $\left(\mathrm{KW}_{2}=2.90, \mathrm{p}=0.41\right.$; Fig. $\left.6 \mathrm{~b}\right)$ or when the outlier gunshot calling (24-25 December 2014 and 3 January 2015; Fig. 4) was excluded $\left(\mathrm{KW}_{2}=1.77, \mathrm{p}=0.41\right.$; Fig. $\left.6 \mathrm{~d}\right)$.

\section{Vessel noise presence and analysis}

Vessel noise was pervasive throughout the study period, occurring on nearly all days of sampling (97\%), including all days with NPRW upcall and gunshot recordings (Fig. 3). It is important to re-emphasize that vessel daily PIC are an indicator of presence (daily number of intervals with vessel noise present/ total intervals sampled per day), and not a measure

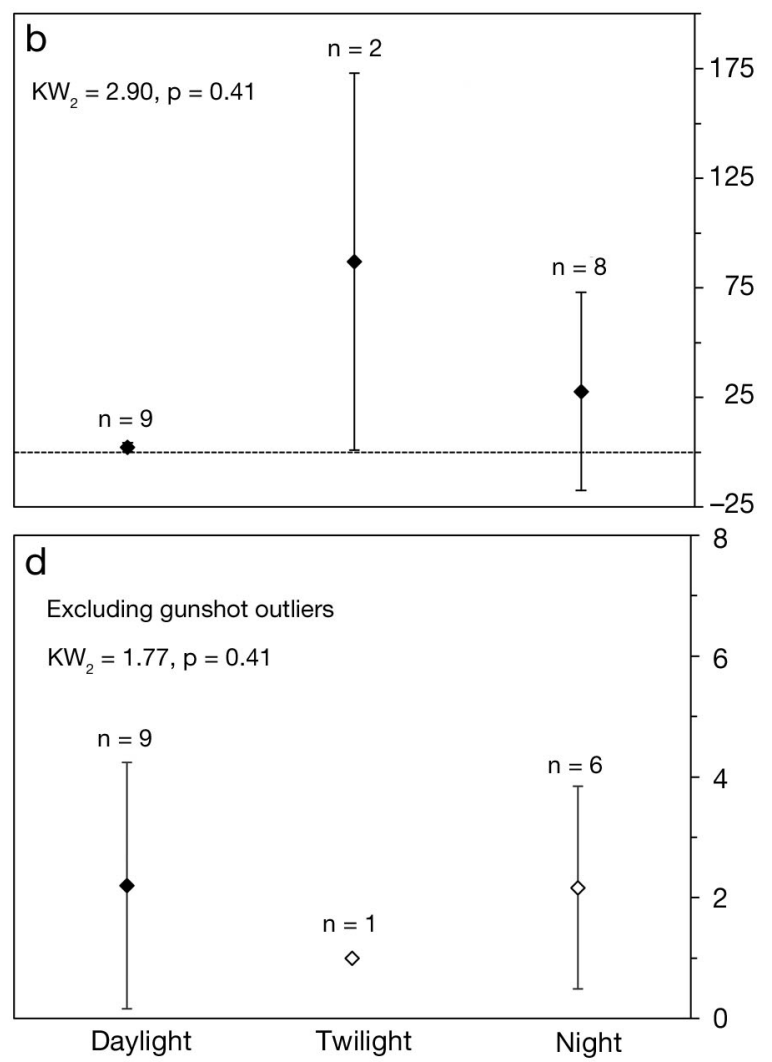

Fig. 6. Average hourly ( $\pm 1 \mathrm{SD}$ ) call detection rate (no. of calls detected $\mathrm{h}^{-1}$ for hours with 60 continuous minutes of sampling) of North Pacific right whale calls by $(\mathrm{a}, \mathrm{c})$ seasonal timeframe (Dec-Feb, Mar-May, Jun-Aug, and Sep-Nov) and (b,d) light regime (daylight, twilight, and night). Panels (c) and (d) include the average hourly call detection rate after the outlier gunshot calling in 2014-15 was excluded (24-25 Dec 2014 and 3 Jan 2015; see Fig. 4), which are denoted with open symbols. Also shown are the number of hours with detection(s) (n), and the results from Kruskal Wallis tests (KW, subscript = degrees of freedom) 
of the sound amplitude of the vessel noise or the number of vessels. For days with NPRW upcalling present, daily vessel PIC was highest on 16 January $2012(89.6 \%)$ and lowest on 25 December 2014 (9.7\%; Fig. 3). For days with NPRW gunshot calling, daily vessel PIC was highest on 11 August 2009 (95.8\%) and lowest on 26 December 2014 (9.2\%; Fig. 3).

When the spectral density percentiles for vessel noise were compared to the baseline conditions (Fig. 7), a difference in $+1.6 \mathrm{~dB}$ was observed in the vessel 50th percentile, as well as $+2.4 \mathrm{~dB}$ in the lower $(1 \%)$ percentile, indicating slightly higher amplitude levels and fewer periods of quiet conditions during vessel presence in the NPRW upcall frequency range.

From the noise analysis, vessel noise was greatest across upcall and gunshot call bands in Dec-Feb, followed by Mar-May, Sep-Nov, and finally Jun-Aug for all AURAL deployments (Fig. 8). The maximum difference in seasonal vessel noise (Dec-Feb $>$ JunAug) for both call types occurred in 2012-13 (6 dB for upcalls and $5 \mathrm{~dB}$ for gunshots) and the lowest in 2014-15 (4 dB for both call types; Fig. 8).

\section{DISCUSSION}

\section{Seasonality of detections}

NPRW were acoustically detected in low, but persistent number throughout the dataset, confirming their presence in the high-traffic Unimak Pass. The detection of NPRW in 3 mooring-years during DecFeb and in 4 mooring-years during Mar-May supports the hypothesis that Unimak Pass is a migratory corridor. The Dec-Feb detections are consistent with a sighting of 4 individual right whales seen transiting this pass on 12 January 1964 (Ivashchenko \& Clapham 2012). Mar-May calls are consistent with a sighting of NPRWs north of Unimak Pass in April 1993 (Shelden et al. 2005), and April is the time of year that NPRWs were first sighted in the vicinity of the Aleutian Islands in a given whaling season (Scarff 1991, Shelden et al. 2005, Smith et al. 2012). These results, combined with the recorded absence of NPRW calls in the SEBS from January to April (Munger et al. 2008), support the timeframe of seasonal migration of NPRW through this Aleutian Pass.

The presence of NPRW vocalizations in all months except October in this dataset is not consistent with the idea that Unimak Pass is used solely as an entry and exit point for whales undertaking a seasonal

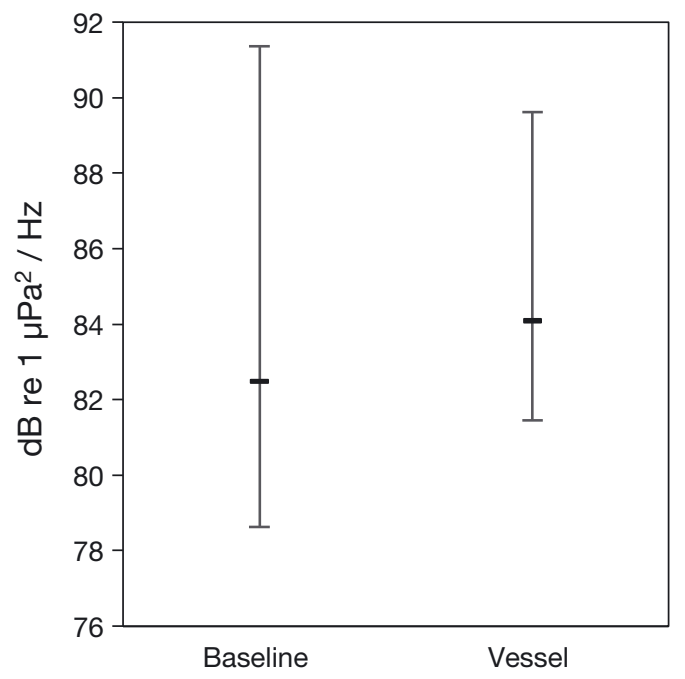

Fig. 7. 50th power spectral density percentiles (medians) and upper (99\%) and lower (1\%) percentiles of vessel noise files and baseline noise files for the mooring-year 2012-13

migration. Nevertheless, the overall low but persistent presence of NPRW calls from June to September is consistent with data from Akutan whaling station, which reported low but consistent catches and sightings of NPRWs from May to September in the vicinity of Unimak Island from 1912 to 1939 (Shelden et al. 2005). These detections are also consistent with 1 NPRW sighted southeast of Unimak Pass in August 2000 (Mellinger et al. 2004) as well as a sighting of 12 NPRWs just north of Unimak Pass in October 2012 (NMFS 2006).

Overall, the findings presented here are ecologically realistic. The low daily calling activity of NPRW throughout the study suggests that NPRW presence within this Aleutian Pass is brief, consistent with transit between the Bering Sea and GOA. However, temporal clustering of gunshots across days in summer (most notably August 2009) suggests either a transit of multiple calling individuals by the hydrophone during a relatively short time-window or milling of individuals within the pass. The summer detections could reflect NPRW foraging within Unimak Pass during favorable conditions. Warm, fresh Alaska Coastal Current (ACC) water flows northward through the pass year-round but is weakest during August (Stabeno et al. 2002, 2016). Because of the weakened flow during summer, colder, saltier Alaska North Slope Current (ANSC) water flows into the pass from the Bering side, resulting in productive fronts and eddies within the pass and along the northern edge that vary in strength on fine temporal scales (e.g. varying with tides and wind patterns; Stabeno et al. 2002, Ladd et al. 2005a,b, Mordy et al. 

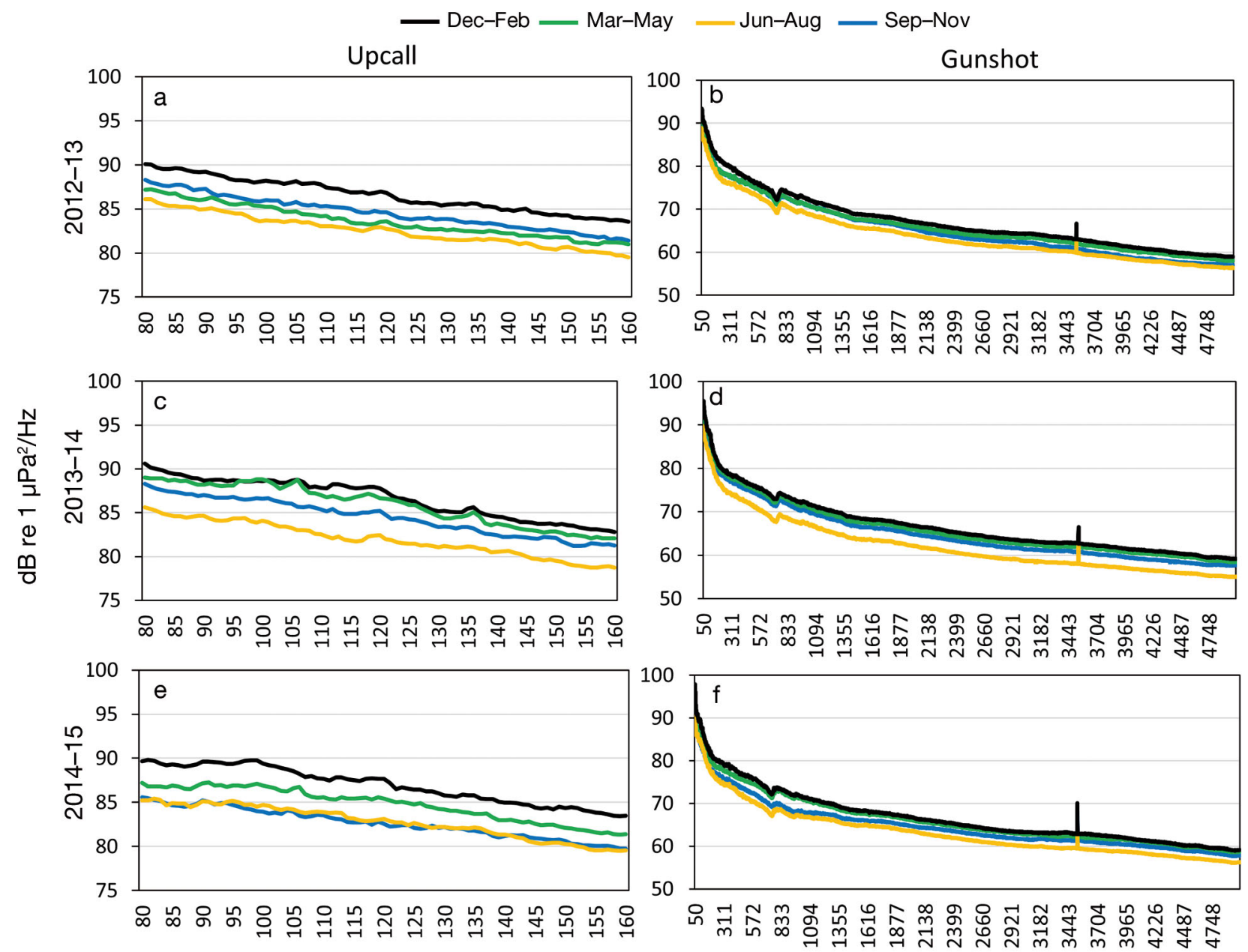

Frequency $(\mathrm{Hz})$

Fig. 8. 50th power spectral density percentiles (medians) of vessel noise files by deployment, $1 \mathrm{~h}, 1 \mathrm{~Hz}$, and $1 \mathrm{~dB}$ (re $1 \mu \mathrm{PA}$ ) resolutions for $(\mathrm{a}, \mathrm{c}, \mathrm{e})$ upcall $(80$ to $160 \mathrm{~Hz})$ and $(\mathrm{b}, \mathrm{d}, \mathrm{f})$ gunshot $(50$ to $5000 \mathrm{~Hz})$ frequency bands by mooring-year $(\mathrm{a}, \mathrm{b}$ : 2012-13; c,d: 2013-14; e,f: 2014-15). Line colors indicate seasonal timeframes. Only data from AURAL recorder deployments were used in the analysis for consistency (Table 1). Peak at $\sim 3800 \mathrm{~Hz}$ of gunshot data is the result of resonance frequency of the hydrophone

2005). These fronts and eddies have been linked to the distribution of other zooplanktivore taxa (Ladd et al. 2005b).

\section{Call detection rates}

There was a lack of support for seasonal or light regime differences in hourly call detection rate, even after the outlier gunshot calling in 2014-15 was removed. The number of acoustic detections may have been too infrequent to reflect underlying trends given the assumption that right whales are transiting the pass. Alternatively, these data suggest that additional factors may influence passage use. As stated previously, although the mean flow through the passes is northward, both ACC and ANSC flow into Unimak Pass, with the relative strength, timing, and mixing of these currents driven by bathymetry, winds, seasons, and tides (Ladd et al. 2005a, Mordy et al. 2005, Stabeno et al. 2016). Therefore, it may be energetically favorable for NPRW to transit during certain tidal cycles. Consequently, individual calls were grouped post-analysis by tidal cycle (flood, ebb, and slack) using data found on the NOAA Tides and Currents website for Scotch Cap, Unimak Pass, AK (https://tidesandcurrents.noaa.gov/). The majority of days with NPRW upcalls and gunshots occurred during slack tide (5 of 7 and 19 of 32 days, respectively), which was reflected in the number of individual calls ( $n=20$ of 31 upcalls and $n=429$ of 480 gunshot calls during slack). These data suggest that tide type may 
influence NPRW presence within this pass. Consequently, given the duty cycle, we may have underrepresented the acoustic presence of NPRWs. Alternatively, these data could reflect tidal differences in call detectability (e.g. fluxes in ambient or self noise from tidal currents).

\section{Masking}

There is no doubt that given the pervasiveness of vessel noise throughout this study (Fig. 3), and the increase in noise levels within the upcall frequency range (Fig. 7), that some NPRW calls could have been masked from detection by our analyst. Expected detection ranges were in the tens of kilometers for both call types (Mellinger et al. 2004). A range of up to $40 \mathrm{~km}$ has been observed for NPRW upcalls and gunshots from hydrophones and long-term recorders 40 to $90 \mathrm{~m}$ deep over the southeastern Bering shelf (SEBS; McDonald \& Moore 2002, Rone et al. 2012, Crance et al. 2017, Thode et al. 2017). Furthermore, while Munger et al. (2011) calculated a theoretical NPRW upcall detection range up to $100 \mathrm{~km}$ over the SEBS during 'low noise conditions' (defined as $72 \mathrm{~dB}$ re $1 \mu \mathrm{Pa}^{2} \mathrm{~Hz}^{-1}$ ), the authors noted that at elevated noise levels (average $80 \mathrm{~dB}$ re $1 \mu \mathrm{Pa}^{2} \mathrm{~Hz}^{-1}$; range 72 to $110 \mathrm{~dB}$ re $1 \mathrm{\mu Pa}^{2} \mathrm{~Hz}^{-1}$ ), 'whales would have to be close (within a few $\mathrm{km}$ ) to the hydrophone for the calls to be collected', p. 4053. A similar elevated ambient noise was observed for upcalls in this study (77-92 dB re $1 \mu \mathrm{Pa}^{2} \mathrm{~Hz}^{-1}$, data not shown). Therefore, we are most likely underreporting the acoustic presence of NPRW in this high-traffic pass, particularly during vessel noise presence conditions. Regardless, NPRW were consistently detected using the upcall from Dec-Feb, confirming that NPRW use this Aleutian Pass during the assumed migratory period from the Bering Sea. The probable reason that there were detections despite the noisy conditions is that the passage is narrow $(\sim 16 \mathrm{~km})$, forcing NPRW to be close to our recorder location when transiting through this area. On the other hand, this narrow passage increases the chances that the vessels are passing close to the whales, which may influence calling behavior. Right whales do respond behaviorally to vessel noise; congeneric right whales upcall louder but less often at a higher frequency in high noise conditions in an attempt to compensate for higher background noise (Parks \& Clark 2007, Parks et al. 2011). Consequently, NRPW may be producing loud upcalls in order to be heard by conspecifics in this noisy environment.

\section{Intermittent detections}

While NPRW calls occurred in all years and seasonal timeframes, detections were clustered in time and intermittent throughout the study period. In fact, the hourly call detection rate for a given day also constituted the daily call detection rate (calls $\mathrm{d}^{-1}$ ) for all but one day (26 December 2014), which was low $\left(<5 \mathrm{~d}^{-1}\right)$ for the majority of days. This low call detection rate is reasonable given that NPRWs are assumed to be extremely rare and only briefly occupy the pass. NPRWs may have passed silently by the hydrophone. Their calls could also have been missed if they were transiting the pass while the hydrophone was not actively recording (i.e. due to duty cycle).

Interestingly, though, the general low call detection rate is in stark contrast to the large number of detections that occurred over $3 \mathrm{~d}$ in mooring-year 2014-15 (398 of 480 total calls). The maximum call detection rate in this time period $\left(176\right.$ calls $^{-1}$ detected on 24 December 14) is still well within the normal range of one NPRW gunshot calling based on focal follow data of NPRWs in the SEBS (Jul-Sep; max gunshot call rate 425 calls h$^{-1}$; Crance et al. 2017). Limited focal follow data suggest that female NPRW have a markedly lower gunshot call rate $\left(54.1 \mathrm{~h}^{-1}\right)$ than males $\left(156.1 \mathrm{~h}^{-1}\right)$, and their gunshot bouts contain irregular ICIs (Crance et al. 2017). Consequently, the high daily call detection rate in winter 2016 suggests that at least one male NPRW may have been present (Crance et al. 2017). In addition, the high variance in winter gunshot calling across deployments does not eliminate the potential presence of females during this timeframe. Nevertheless, data on winter call rates of NPRW have not yet been collected, and the female NPRW call rate data are extremely limited (Crance et al. 2017). We are unable to determine whether the variability in calling throughout the study reflect sex-based differences in call behavior or alternatively reflect a general change in behavior in the pass (milling vs. transiting vs. sexual display) or possible variability in the number of calling individuals.

Additionally, the variability in calling throughout the dataset could also be the result of NPRWs using multiple Aleutian Passes for transit. Passage use may be driven by fluctuating seasonal and annual biophysical conditions, such as currents or food availability (Coyle 2005, Ladd et al. 2005a,b, Mordy et al. 2005). Also, passage use may simply be dictated by proximity of an individual to a given pass when the individual decides to transit between the Bering Sea and other areas. Acoustic sampling in additional 
passes within the eastern Aleutian Chain would be helpful in further explaining these findings.

The higher detection of gunshot calls compared with upcalls in this dataset is reasonable given that gunshot calls are the assumed primary call type of NPRWs (Crance et al. 2017). However, this difference in detection could have been influenced by the dutycycled analysis given the irregular nature of right whale upcalls compared with gunshots and the pervasiveness of vessel noise with a stronger influence on the narrower frequency band upcalls compared to broadband gunshots. As stated previously, right whale upcalling is characterized by irregular timing of calls ( $>5 \mathrm{~s}$ ) followed by long periods of acoustic inactivity (Clark 1982, Matthews et al. 2001, McDonald \& Moore 2002, Parks \& Tyack 2005, Munger et al. 2008). In contrast, the ICI is shorter ( 0.5 to $5 \mathrm{~s}$ ) and the calling sequences longer for gunshot bouts, resulting in an estimated 50-fold greater average hourly call rate of NPRW gunshots (228.3 calls h ${ }^{-1}$ ) compared to NPRW upcalls (4.3 calls h ${ }^{-1}$; Crance et al. 2017).

Overall, these data illustrate the usefulness of passive acoustic analysis in monitoring rare marine mammal species. The intermittent presence of NPRW across season warrants year-round continuous sampling in this pass to represent the true acoustic presence of this Critically Endangered species in this high-traffic region. However, even with these dutycycled data, it is clear that NPRW use this pass during and outside of the assumed migratory period.

\section{Extensive vessel presence and population recovery}

The detection of NPRWs at Unimak Pass remains a major concern given the pervasive vessel noise in this area. Potential acute threats to this population of NPRW include entanglement in fishing gear and ship strike. Although there is limited evidence for either threat, the remote habitat makes detections of anthropogenic mortalities unlikely. Right whales in other parts of the world with high vessel activity are vulnerable to ship strike and entanglement (Knowlton et al. 2012, Kraus et al. 2016, Lanyon \& Janetzki 2016, Meyer-Gutbrod \& Greene 2018). Unimak Pass is a narrow channel $(\sim 16 \mathrm{~km})$, increasing the likelihood of interaction. Furthermore, the finding that NPRWs were persistently detected during Dec-Feb, which coincides with the seasonal timeframe that vessel noise was highest, is of concern. Elevated noise levels from anthropogenic noise impact the behavior (Parks \& Clark 2007, Parks et al. 2011), physiology (Rolland et al. 2012), and area over which marine mammals, including right whales, can communicate (Cholewiak et al. 2018). Acoustic communication may be vital for the success of small marine mammal populations (Tyack 2008). Poor weather in winter months may force ships to take a sheltered route through the passes of the eastern Aleutian Islands compared with traveling parallel to the Aleutians during other seasons, further increasing the likelihood of collision. A single death of a NPRW (especially a reproductive female) from ship strike would be a major blow to this small population.

Unfortunately, interactions of NPRWs and anthropogenic sources will likely increase with impending climate change. Climate models conservatively predict major changes to ice extent throughout the Chukchi and Bering seas by 2050 (Stroeve et al. 2007, Wang et al. 2012). Trans-Arctic ship traffic is anticipated to increase due to an ice-free Northwest Passage and Northern Sea Route, increasing the likelihood of NPRW collision with ships in Unimak Pass and the SEBS. Unimak Pass is also increasingly used by ships taking a Great Circle route through the Bering Sea from North America and Asia (Nuka Research and Planning Group 2014, 2016). As stated previously, $60 \%$ of the deep draft vessels involved in international trade that transited Unimak Pass in 2012 were cargo vessels, followed by $24 \%$ container vessels (Nuka Research and Planning Group 2014). It is therefore imperative that management strategies be implemented for NPRWs, especially in high vessel traffic areas such as Unimak Pass, to provide the population a chance to recover.

Acknowledgements. We thank the numerous field technicians involved in mooring deployment and retrieval as well as the captains and crews of the FV 'Aquila', FV 'Alaskan Enterprise' and FV 'Mystery Bay'. We thank Nissa Ferm, Jessica Kimber, and 3 anonymous reviewers whose comments greatly improved the manuscript. We also thank Kate Stafford for suggesting the tidal cycle analysis. We thank the International Fund for Animal Welfare and the Marine Mammal Commission for generously funding this analysis. Funds for recorder and mooring component purchasing, deployment, and retrieval were provided by the BOEMfunded ARCWEST and NPRW projects (IA \#s M12PG00021, M07RG13267). The findings and conclusions in the paper are those of the authors and do not necessarily represent the views of the National Marine Fisheries Service. Reference to trade names does not imply endorsement by the National Marine Fisheries Service, NOAA.

\section{LITERATURE CITED}

Bort J, Van Parijs SM, Stevick PT, Summers E, Todd S (2015) North Atlantic right whale Eubalaena glacialis vocalization patterns in the central Gulf of Maine from October 
2009 through October 2010. Endang Species Res 26: 271-280

Brownell Jr RL, Clapham PJ, Miyashita T, Kasuya S (2001) Conservation status of North Pacific right whales. J Cetacean Res Manage 2:269-286

Cholewiak D, Clark CW, Ponirakis D, Frankel A and others (2018) Communicating amongst the noise: modeling the aggregate influence of ambient and vessel noise on baleen whale communication space in a national marine sanctuary. Endang Species Res 36:59-75

Clapham PJ, Good C, Quinn SE, Reeves RR, Scarff JE, Brownell RL Jr (2004) Distribution of North Pacific right whales (Eubalaena japonica) as shown by 19th and 20th century whaling catch and sighting records. J Cetacean Res Manag 6:1-6

Clark CW (1982) The acoustic repertoire of the southern right whale, a quantitative analysis. J Anim Behav 30: 1060-1071

Clark CW (1983) Acoustic communication and behavior of southern right whales (Eubalaena australis). In: Payne RS (ed) Communication and behavior of whales. American Association for the Advancement of Science Selected Symposium 76. Westview Press, Boulder, CO, p 163-198

Clark CW, Clapham PJ (2004) Acoustic monitoring of a humpback whale (Megaptera novaeangliae) feeding ground shows continual singing into late spring. Proc R Soc B 271:1051-1057

* Cole TV, Hamilton P, Henry AG, Duley P, Pace RM III, White BN, Frasier T (2013) Evidence of a North Atlantic right whale Eubalaena glacialis mating ground. Endang Species Res 21:55-64

Coyle KO (2005) Zooplankton distribution, abundance and biomass relative to water masses in eastern and central Aleutian Island passes. Fish Oceanogr 14:77-92

Crance JL, Berchok CL, Keating JL (2017) Gunshot call production by the North Pacific right whale, Eubalaena japonica, in the southeastern Bering Sea. Endang Species Res 34:251-267

Cummings WC, Fish JF, Thompson PO (1972) Sound production and other behavior of southern right whales, Eubalaena glacialis. San Diego Society of Natural History, Transactions 17:1-14

Dugan PJ, Ponirakis DW, Zollweg JA, Pitzrick MS and others (2011) SEDNA-Bioacoustic Analysis Toolbox: Matlab platform to support high performance computing, noise analysis, event detection and event modeling. IEEE Xplore. OCEANS-11, Kona, HI

Ford JK, Pilkington JF, Gisborne B, Frasier TR, Abernethy RM, Ellis GM (2016) Recent observations of critically endangered North Pacific right whales (Eubalaena japonica) off the west coast of Canada. Mar Biodivers Rec 9: 50

Gendron D, Lanham S, Carwardine M (1999) North Pacific right whale (Eubalaena glacialis) sighting south of Baja California. Aquat Mamm 25:31-34

Ivashchenko YV, Clapham PJ (2012) Soviet catches of right whales Eubalaena japonica and bowhead whales Balaena mysticetus in the North Pacific Ocean and the Okhotsk Sea. Endang Species Res 18:201-217

Josephson E, Smith TD, Reeves RR (2008) Historical distribution of right whales in the North Pacific. Fish Fish 9: 155-168

Kennedy AS, Salden DR, Clapham PJ (2012) First high to low latitude match of an eastern North Pacific right whale (Eubalaena japonica). Mar Mamm Sci 28:E539-E544
Knowlton AR, Hamilton PK, Marx MK, Pettis HM, Kraus SD (2012) Monitoring North Atlantic right whale Eubalaena glacialis entanglement rates: a 30 yr retrospective. Mar Ecol Prog Ser 466:293-302

Kraus SD, Prescott JH, Knowlton AR, Stone GS (1986) Migration and calving of right whales (Eubalaena glacialis) in the western North Atlantic. Rep Int Whaling Comm (Special Issue 10) 139-144

Kraus SD, Kennedy RD, Mayo CA, McLellan WA, Moore MJ, Nowacek DP (2016) Recent scientific publications cast doubt on North Atlantic right whale future. Front Mar Sci 3:137

* Ladd C, Hunt JL Jr, Mordy CW, Salo SA, Stabeno PJ (2005a) Marine environment of the eastern and central Aleutian Islands. Fish Oceanogr 14:22-38

* Ladd C, Jahncke J, Hunt GL Jr, Coyle KO, Stabeno PJ (2005b) Hydrographic features and seabird foraging in Aleutian passes. Fish Oceanogr 14:178-195

Lammers MO, Brainard RE, Au WWL, Mooney TA, Wong K (2008) An ecological acoustic recorder (EAR) for longterm monitoring of biological and anthropogenic sounds on coral reefs and other marine habitats. J of the Acoust Soc Am 123:1720-1728

Lanyon JM, Janetzki H (2016) Mortalities of Southern Right Whales (Eubalaena australis) in a subtropical wintering ground, Southeast Queensland. Aquat Mamm 42:470-475

Matthews JN, Brown S, Gillespie D, Johnson M and others (2001) Vocalization rates of the North Atlantic right whale (Eubalaena glacialis). J Cetacean Res Manag 2: 227-234

Matthews LH (1983) Notes on the southern right whale, Eubalaena australis. Discovery Rep 17:169-182

Matthews LP, McCordic JA, Parks SE (2014) Remote acoustic monitoring of North Atlantic right whales (Eubalaena glacialis) reveals seasonal and diel variations in acoustic behavior. PLOS ONE 9:e91367

McDonald MA, Moore SE (2002) Calls recorded from North Pacific right whales (Eubalaena japonica) in the eastern Bering Sea. J Cetacean Res Manag 4:261-266

*McSweeney DJ, Chu KC, Dolphin WF, Guinee LN (1989) North Pacific humpback whale songs: a comparison of southeast Alaskan feeding ground songs with Hawaiian wintering ground songs. Mar Mamm Sci 5:139-148

*Mellinger DK, Stafford KM, Moore S, Munger L (2004) Detection of North Pacific right whale (Eubalaena japonica) calls in the Gulf of Alaska. Mar Mamm Sci 20: 872-879

Merchant ND, Barton TR, Thompson PM, Pirotta E, Dakin DT, Dorocicz J (2013) Spectral probability density as a tool for ambient noise analysis. J Acoust Soc Am 133: EL262-EL267

Meyer-Gutbrod EL, Greene CH (2018) Uncertain recovery of the North Atlantic right whale in a changing ocean. Glob Change Biol 24:455-464

* Mordy CW, Stabeno PJ, Ladd C, Zeeman S, Wisegarver DP, Salo SA, Hunt GL Jr (2005) Nutrients and primary production along the eastern Aleutian Island Archipelago. Fish Oceanogr 14:55-76

Munger LM, Wiggins SM, Moore SE, Hildebrand JA (2008) North Pacific right whale (Eubalaena japonica) seasonal and diel calling patterns from long-term acoustic recordings in the southeastern Bering Sea, 2000-2006. Mar Mamm Sci 24:795-814

* Munger LM, Wiggins SM, Hildebrand JA (2011) North Pacific right whale up-call source levels and propagation 
distance on the southeastern Bering Sea shelf. J Acoust Soc Am 129:4047-4054

National Marine Fisheries Service (2006) Review of the status of the Right Whales in the North Atlantic and North Pacific Oceans. NOAA NMFS, Silver Spring, MD. www. fisheries.noaa.gov/resource/document/review-status-rightwhales-north-atlantic-and-north-pacific-oceans

Nuka Research and Planning Group (2014) 2012 transits of Unimark Pass. Aleutian Islands Risk Assessment Advisory Panel and Management Team, Seldovia, AK, http:// aleutianriskassessment.com/files/141125_AIRA_Unimak TransitsUpdate_FINAL.pdf

Nuka Research and Planning Group (2016) Bering Sea Vessel Traffic Risk Analysis, December 2016. Ocean Conservancy, available at https://oceanconservancy.org/wpcontent/uploads/2017/01/bering-sea-vessel-traffic-1.pdf

* Parks SE, Clark CW (2007) Short- and long-term changes in right whale calling behavior: the potential effects of noise on acoustic communication. J Acoust Soc Am 122: 3725-3731

Parks SE, Tyack PL (2005) Sound production by North Atlantic right whales (Eubalaena glacilias) in surface active groups. J Acoust Soc Am 117:3297-3306

Parks SE, Hamilton PK, Kraus SD, Tyack PL (2005) The gunshot sound produced by male north Atlantic right whales (Eubalaena glacialis) and its potential function in reproductive advertisement. Mar Mamm Sci 21: 458-475

Parks SE, Johnson M, Nowacek D, Tyack PL (2011) Individual right whales call louder in increased environmental noise. Biol Lett 7:33-35

Payne RS, McVay S (1971) Songs of humpback whales. Science 173:585-597

R Core Team (2015) R: a language and environment for statistical computing. R Foundation for Statistical Computing, Vienna. www.R-project.org

Reilly SB, Bannister JL, Best PB, Brown M and others (2008) Eubalaena japonica (Northeast Pacific subpopulation). In: IUCN Red List of Threatened Species, Version 2011.1. www.iucnredlist.org

Rolland RM, Parks SE, Hunt KE, Castellote M and others (2012) Evidence that ship noise increases stress in right whales. Proc R Soc B 279:2363-2368

Rone BK, Berchok CL, Crance JL, Clapham PJ (2012) Using air deployed passive sonobuoys to detect and locate critically endangered North Pacific right whales. Mar Mamm Sci 28:E528-E538

Scarff JE (1991) Historic distribution and abundance of the right whale (Eubalaena glacialis) in the North Pacific, Bering Sea, Sea of Okhotsk and Sea of Japan from the Maury Whale Charts. Rep Int Whaling Comm 41: $467-489$

Editorial responsibility: Robert Harcourt, Sydney, New South Wales, Australia
Scarff JE (2001) Preliminary estimates of whaling-induced mortality in the 19th century North Pacific right whale (Eubalaena japonicus) fishery, adjusting for struck-butlost whales and non-American whaling. J Cetacean Res Manag Spec Issue 2:261-268

Shelden KE, Moore SE, Waite JM, Wade PR, Rugh DJ (2005) Historic and current habitat use by North Pacific right whales Eubalaena japonica in the Bering Sea and Gulf of Alaska. Mammal Rev 35:129-155

* Širović A, Johnson SC, Roche LK, Varga LM, Wiggins SM, Hildebrand JA (2015) North Pacific right whales (Eubalaena japonica) recorded in the northeastern Pacific Ocean in 2013. Mar Mamm Sci 31:800-807

Smith TD, Reeves RR, Josephson EA, Lund JN (2012) Spatial and seasonal distribution of American whaling and whales in the age of sail. PLOS ONE 7:e34905

Stabeno PJ, Reed RK, Napp JM (2002) Transport through Unimak Pass, Alaska. Deep Sea Res II 49:5919-5930

* Stabeno PJ, Danielson SL, Kachel DG, Kachel NB, Mordy CW (2016) Currents and transport off the eastern Bering Sea shelf: an integration of over 20 years of data. Deep Sea Res II 134:13-29

Stroeve J, Holland MM, Meier W, Scambos T, Serreze M (2007) Arctic sea ice decline: faster than forecast. Geophys Res Lett 16:L09501

* Thode A, Bonnel J, Thieury M, Fagen A and others (2017) Using nonlinear time warping to estimate North Pacific right whale calling depths in the Bering Sea. J Acoust Soc Am 141:3059-3069

* Thompson PO, Cummings WC, Ha SJ (1986) Sounds, source levels, and associated behavior of humpback whales, Southeast Alaska. J Acoust Soc Am 80:735-740

Tyack PL (2008) Implications for marine mammals of largescale changes in the marine acoustic environment. J Mammal 89:549-558

*Wade P, Heide-Jørgensen MP, Shelden K, Barlow J and others (2006) Acoustic detection and satellite-tracking leads to discovery or rate concentration of endangered North Pacific right whales. Biol Lett 2:417-419

* Wade PR, Kennedy A, LeDuc R, Barlow J and others (2011a) The world's smallest whale population? Biol Lett 7:83-85

*Wade PR, De Robertis A, Hough KR, Booth R and others (2011b) Rare detections of North Pacific right whales in the Gulf of Alaska, with observations of their potential prey. Endang Species Res 13:99-109

*Wang M, Overland JE, Stabeno P (2012) Future climate of the Bering and Chukchi Seas projected by global climate models. Deep Sea Res II 65-70:46-57

*Wright DL, Berchok CL, Crance JL, Clapham PJ (2018) Acoustic detection of the critically endangered North Pacific right whale in the northern Bering Sea. Mar Mamm Sci (in press) doi:10.1111/mms.12521

Submitted: March 1, 2018; Accepted: July 18, 2018

Proofs received from author(s): September 2, 2018 